\title{
Improving irrigation practice in New Zealand
}

\author{
R. J. Martin ${ }^{1}$, S. M. Thomas ${ }^{1}$, D. J. Bloomer ${ }^{2}$, R. F. Zyskowski ${ }^{1}$, \\ P. D. Jamieson ${ }^{1}$, W. J. Clarke-Hill ${ }^{3}$ \& C. G. L. Pennell ${ }^{3}$ \\ ${ }^{I}$ Crop and Food Research, New Zealand \\ ${ }^{2}$ Page Bloomer Associates Ltd, New Zealand \\ ${ }^{3}$ AgResearch, New Zealand
}

\begin{abstract}
The Canterbury Plains are the major cropping area, and an increasingly important dairying area, in New Zealand. Irrigation is necessary on most of the Plains to achieve high productivity. However, competition for limited water resources means that farmers increasingly have to justify their demands for water. Farmers need to know when to irrigate, how much water to apply, and the yield penalty if the crop is not irrigated. For annual arable crops, we have used the maximum potential soil moisture deficit (MPSMD) model and a large rainshelter to answer these questions. Total or economic yield of nearly all the crops tested decreased linearly as MPSMD increased, regardless of the timing of drought. The slope of the regression line is the yield loss with increasing MPSMD. For ryegrass dairy pastures, which grow throughout the year, the model has been adapted to simulate actual soil moisture changes. As most farmers do not measure pasture production directly, we have developed a model for potential pasture production, and a simple relationship between grass growth restrictions and actual soil moisture deficits, that fits experimental farm data. Farmers can also reduce the amount of water they apply by improving the water application efficiency of their irrigation systems. Protocols had been developed to identify causes of poor performance in the field, and how these may be addressed. This information is being used by farmers to improve their irrigation decisions, and irrigation system performance, and has been included in decision support systems for arable and vegetable farmers, and is being developed for dairy farmers.
\end{abstract}

Keywords: drought, crops, pasture, irrigation application efficiency, rainshelter, modelling, decision support systems. 


\section{Introduction}

The Canterbury Plains of the South Island of New Zealand lie in the rain shadow east of the Southern Alps mountain range, and can experience drought at any time of the year. Daily potential evapotranspiration often exceeds $6 \mathrm{~mm} /$ day over summer. This is double the mean summer daily rainfall, which has a coefficient of variation of $42 \%$ [1]. Soil water storage over much of the Plains is restricted because of shallow soils, with less than $30 \mathrm{~cm}$ soil depth over gravel [2], and so irrigation is vital to achieve the high productivity essential for profitability in a deregulated agricultural economy.

Irrigation accounts for $70 \%$ of all water used in New Zealand and contributes USD500M to the local economy [3]. The area under irrigation has increased four fold over the past 10 years to 475,700 ha, mainly under intensive cropping or dairying. Demand for irrigation has placed pressure on the limited river and aquifer water sources. Farmers now have increasingly to justify their demands for irrigation water, and regional authorities are looking at ways to ensure that farmers efficiently use the water that they are allocated [4].

The questions that farmers need to ask are when to irrigate, how much to put on, and the yield penalty if the crop is not irrigated or only partially irrigated. Armed with this information, they can make decisions that use the water resource more efficiently, and achieve the best economic outcome on both a crop and farm scale.

\section{Arable crops}

To answer the questions posed above, farmers need to know how dry their soil is. This is time consuming and expensive to measure directly. However, we have found that, the model of Penman [5], as refined by French and Legg [6], works well for annual arable crops. This model quantifies the yield response to drought by using the maximum potential soil moisture deficit (MPSMD) experienced during the growth of the crop as the measure of stress. Potential soil moisture deficit (PSMD) is readily calculated from potential evapotranspiration (PET), rainfall and irrigation data, and has practical meaning in that PSMD can be equated with irrigation applications (or lack of them). Responses to the MPSMD are given in terms of reductions in yield below the much more stable fully irrigated yield. The model produces two meaningful numbers: a critical deficit beyond which yield is reduced, and a reduction in yield per unit of potential deficit when the critical deficit is exceeded.

The model needs to be calibrated for individual crops, as they differ in their susceptibility to drought. We have used a mobile automatic rainshelter [7] to exclude rainfall from experimental plots, which are otherwise exposed to normal weather. This has allowed us to reliably impose a range of drought treatments, based on actual soil moisture, which have included timing and duration of drought periods, and irrigation amounts and frequencies. Up to twelve irrigation treatments, based on timing or intensity of drought, were set up for each of the experimental crops. The PSMD was calculated for each treatment by adding the 
maximum weekly Penman PET from the fully irrigated control treatment to the irrigation deficit (the difference between the amount of water applied to the treatment and to the fully irrigated control). The deficit was adjusted for incomplete ground cover using the modified model of Ritchie [8].

Total, grain, root or tuber yield of all the crops tested, with the exception of oats and white clover seed, generally decreased linearly as the MPSMD experienced during crop growth increased (Figure 1). The slope of the regression line between yield and MPSMD is the yield loss with increasing deficit. This varies from $8 \mathrm{~kg} / \mathrm{ha} / \mathrm{mm}$ for peas [10] up to $25 \mathrm{~kg} / \mathrm{ha} / \mathrm{mm}$ for barley [11]. A critical deficit, below which there is no loss in yield with changing deficit, was able to be determined analytically for wheat [11], but not for any of the other crops.

This linear reduction in yield with increasing deficit occurred regardless of the timing of drought. Consequently economic yield in most crops was related to the intensity and not the timing of drought. How the drought stress influences yield components can vary with timing of stress, as grain size and harvest index in some crops were reduced by late drought $[10,11]$.

In oats and white clover, frequent irrigation to maintain very small deficits reduced yield, due to excessive vegetative growth, causing lodging in oats [12], and shading of the flowers, and hence reduced pollination, in white clover [13]. In these cases, stress at a particular growth stage is beneficial for seed production, but not for total dry matter production.

The relationship between crop yield and MPSMD is also affected by the water holding capacity (WHC) of the soil; the lower the WHC, the lower the yield at a given MPSMD. However, we have successfully extrapolated the results from the rainshelter experiments to other soil types by adjusting the model for crop rooting depth (about $0.8 \mathrm{~m}$ for peas to about $2 \mathrm{~m}$ for maize), depth of soil (WHC $165 \mathrm{~mm} / \mathrm{m})$ to gravel $(55 \mathrm{~mm} / \mathrm{m})$ or to a pan, which impedes rooting [14].

The MPSMD model provides very straightforward calculations of the value of irrigation, capable of being done quite simply in a spreadsheet or even on paper. However, we have developed more complete DSSs [15] based on simulation models such as Sirius [16] that deal with the crop in mode detail, keep a proper water balance including an estimate of the actual soil moisture deficit (ASMD) through time.

\section{Perennial pastures}

One of the main advantages of simulation models is that they don't need an estimate of potential yield - they account for yield forming processes through the life of the crop. This is particularly important for perennial pastures, which continue to grow through the summer and autumn, when accumulated potential deficits are high, but rainfall can stimulate growth, or if potential deficits continue through the winter.

So we have to use ASMD to account for these features of perennial pasture. ASMD can be measured on farms by numerous methods, such as using neutron 
probes or time domain transmission. It can also be calculated from PET using models of varying complexity. We have used a simplified version of a published model [17] using soil available WHC, depth and bulk density, together with pasture cover, rainfall and irrigation, to calculate actual evapotranspiration (AET) from PET. Model outputs have related well to field measurements under grazed pasture (Figure 2).
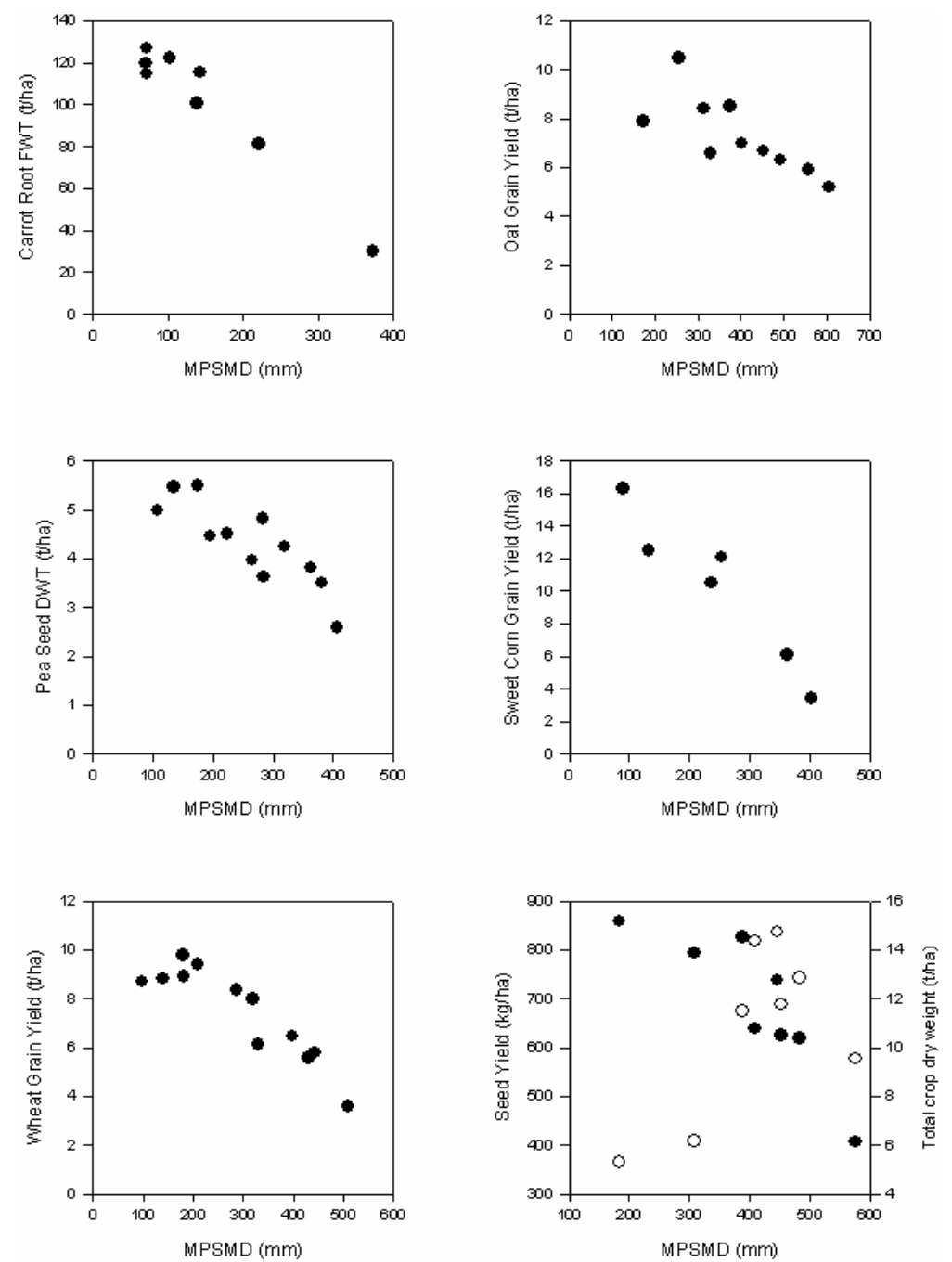

Figure 1: Effect of maximum potential soil moisture deficit (MPSMD) on yield of carrot roots, oat grain, pea seed, sweet corn fresh grain yield, wheat grain yield and white clover total biomass $(\bullet)$ and seed (०) yield (from [9]). 
We have determined actual ryegrass pasture growth rates from pasture cuts in fields on high performing commercial dairy farms in Canterbury. These farms produce up to $18,000 \mathrm{~kg}$ pasture dry matter $(\mathrm{DM}) / \mathrm{ha} / \mathrm{year}$ under rotational grazing, and are irrigated and fertilised to avoid any restrictions on growth. The highest performing fields produced $0.4 \mathrm{~kg}$ of DM/MJ of intercepted solar radiation (the upper line in Figure 2). For the development of the model, we have taken this to be the potential growth rate under non-limiting conditions on dairy farms in Canterbury. Using this growth rate, a relationship between light interception and pasture mass, and a relationship between yield and AET similar to those with PET in Figure 1, we have successfully predicted pasture growth under very different irrigation regimes elsewhere in Canterbury. Figure 3 shows predicted and actual cumulative DM yields for rostered border-dyked flood irrigated pasture on very shallow soils under sheep grazing, compared to predicted yields on high performing dairy farms under sprinkler irrigation on deep soils.

\section{Irrigation application efficiency}

Figure 2 shows that fields on some dairy farms produced only about $60 \%$ of the measured pasture DM yield of the four highest producing farms, and Figure 3 that the surface irrigated sheep fields were producing only about a third of the measured pasture DM compared to those highest producing dairy farms. One of the major reasons for these differences is poor irrigator performance on farm.

We have evaluated the performance of several sprinkler irrigation systems used for irrigating pasture under normal operating conditions in the field. Figure 4 is an example of a centre pivot irrigator on a dairy farm where the measured radial low quarter distribution uniformity [19] was 0.76 , which is rated only fair for a centre pivot. Problems specific to this irrigator included incorrectly operating sprinklers (especially by the towers), insufficient pressure, and wheel track rutting. On other monitored farms with rotating boom irrigators, excessive application rates and depths, variable operating speeds and distances between runs were identified as causes of poor uniformity. Multiple spray line systems had very poor uniformities on farm (as low as 35\%), partly due to poor sprinkler spacing, throw and pattern, and insufficient system pressure. In addition, the distribution pattern of rotating boom and multiple spray line systems was greatly affected by wind speed and direction in the windy Canterbury environment [1].

On surface flood irrigation schemes, where water is supplied on a roster, irrigation efficiencies are lower, ranging from 31 to $61 \%$, the variation being due mainly to variable flow rates and over-irrigation if irrigation restrictions were forecast [20]. Improvements in border-dyke construction techniques, such as laser levelling, can increase irrigation efficiencies considerably, but they are still very variable on-farm [21]. Surface schemes are often located on stony soils in New Zealand, and up to two thirds of the applied water can be lost through drainage [20]. 
154 Sustainable Irrigation Management, Technologies and Policies

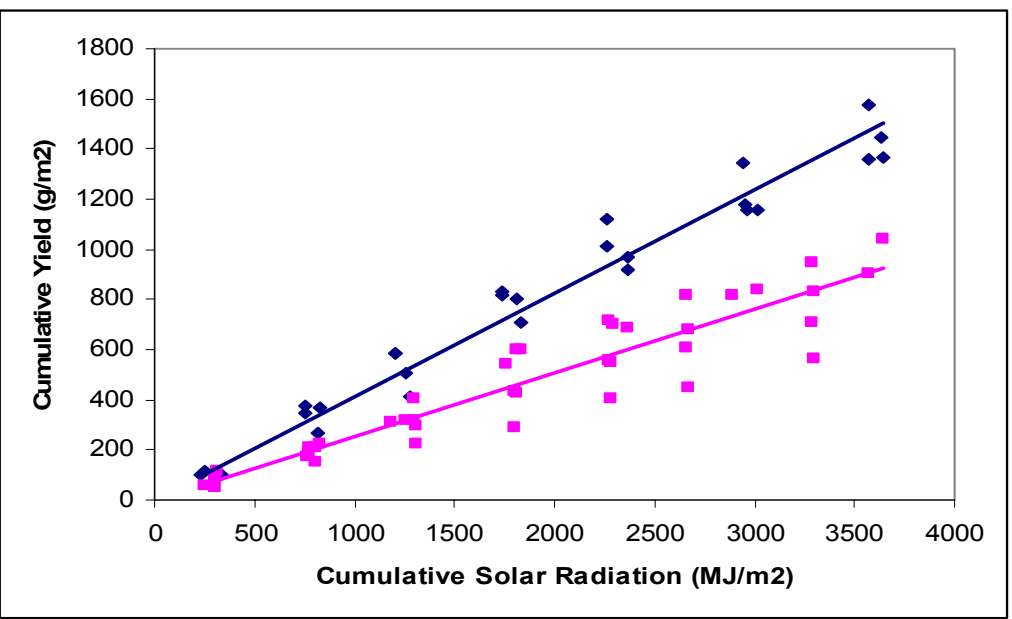

Figure 2: Cumulative dry matter yield per hectare versus total incoming solar radiation from the top four monitored grazed dairy fields $(\boldsymbol{\Delta}$, slope $\left.0.412, r^{2} 0.97\right)$ and from another six fields ( $\square$, slope $\left.0.253, \mathrm{r}^{2} 0.88\right)$.

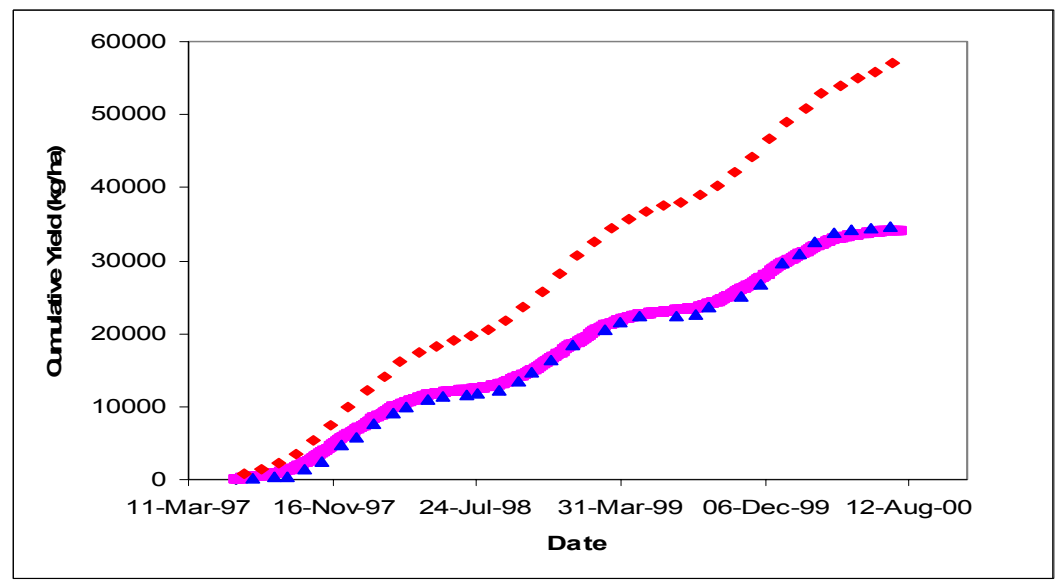

Figure 3: $\quad$ Measured ( $\boldsymbol{\Delta}$ ) and modelled ( $\mathbf{0}$ ) cumulative pasture dry matter yield over three years on a sheep farmlet study under flood irrigation [18], and modelled pasture dry matter yields $(\bullet)$ from the high performance dairy farms in Figure 2.

To assess and improve actual-on farm irrigation system performance, a code of practice and computer software has been developed for evaluation of sprinkler irrigation systems in New Zealand [19]. Protocols have been developed for an on site evaluation of an irrigation system using selected measurements to describe the performance of the system, and its management, and to identify causes of poor performance and how these may be addressed. The primary focus 
is to determine distribution uniformity, application rates and depths, and the causes of non-uniformity. Based on these measures, clear recommendations are made to the farmer on how to improve irrigator system performance.

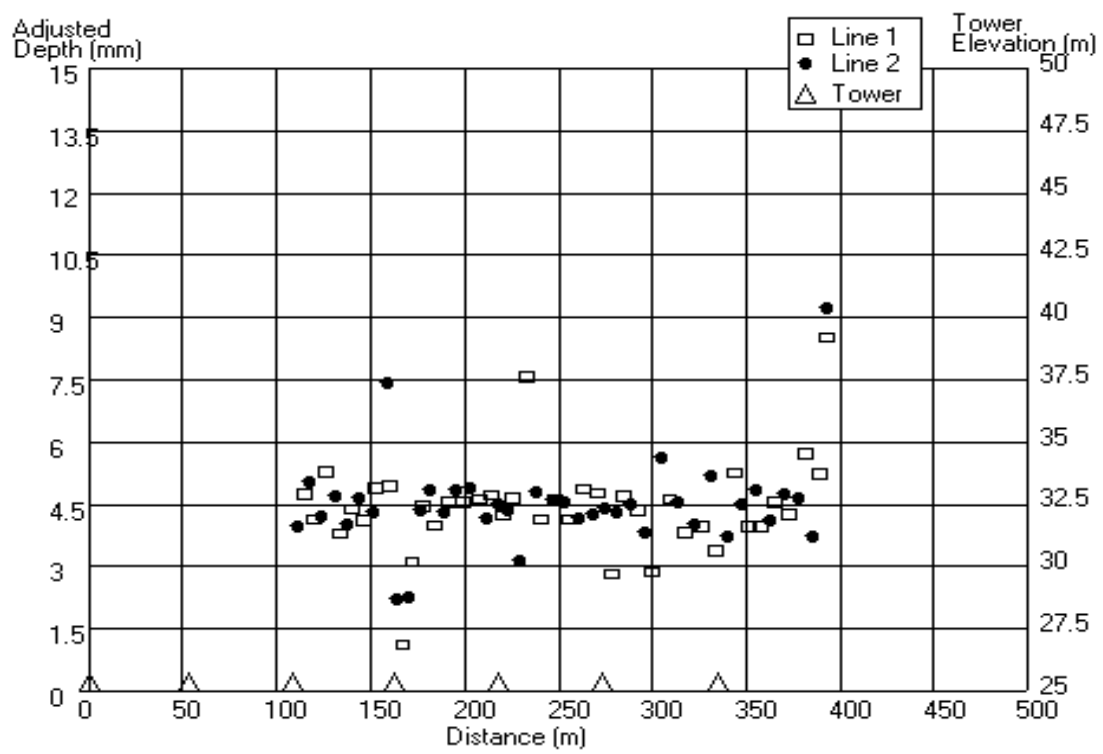

Figure 4: Application depth adjusted for distance along the boom of a centre pivot irrigator operating on a commercial dairy farm in Canterbury, New Zealand.

\section{Applications}

The information from these experiments has enabled clear irrigation scheduling information to be given to farmers. It has also been included in computerised decision support systems developed for wheat, pea, maize, potato and carrot farmers in New Zealand, which enable farmers to see the effects of altering their irrigation and other practices on estimated yields and grain nitrogen [14, 15].

The wheat calculator is now commercially available in New Zealand. An input screen image from this programme, where farmers can see the effects of adjusting irrigation timings and amounts, is shown in Figure 5, and an output screen, which shows the predicted effects of a selected irrigation regime on soil moisture deficits, in Figure 6. A simpler model based on data presented here is being developed into a pasture irrigation calculator for dairy farmers to use in the field.

These, and the improvements in irrigation application efficiency resulting from on farm evaluations of irrigator systems performance, are enabling Canterbury farmers to use their irrigation water more efficiently and economically, benefiting both them and the environment. 
156 Sustainable Irrigation Management, Technologies and Policies

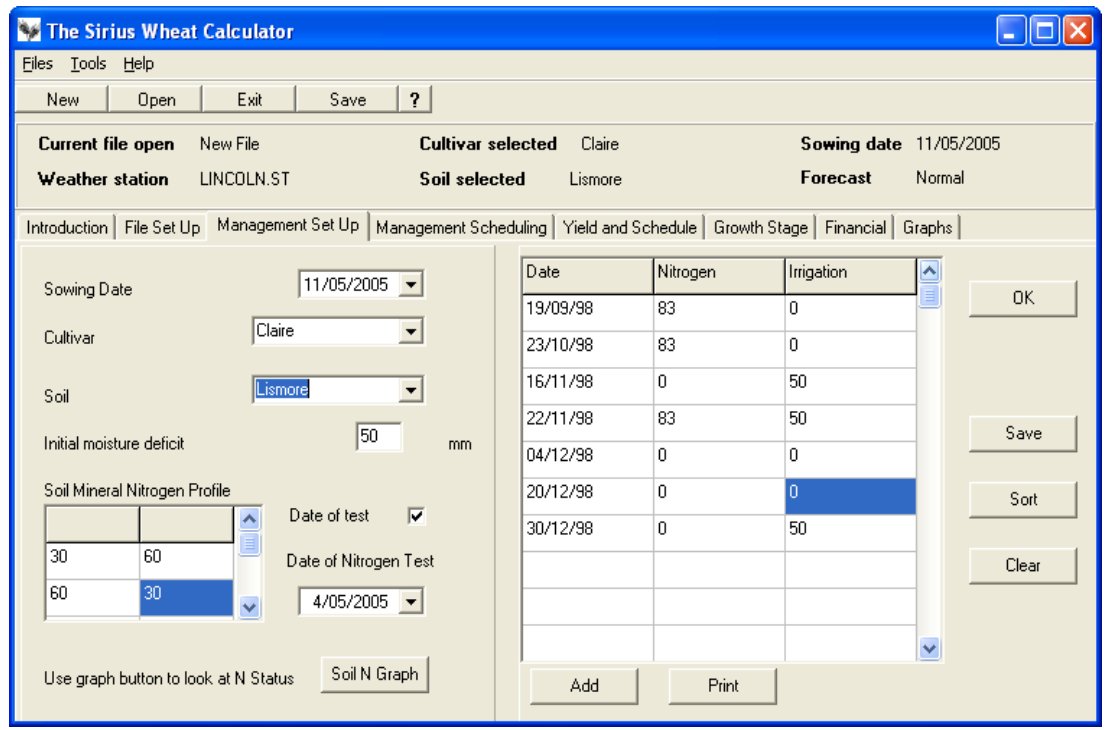

Figure 5: Input screen from the Sirius Wheat Calculator showing the nitrogen and irrigation input page.

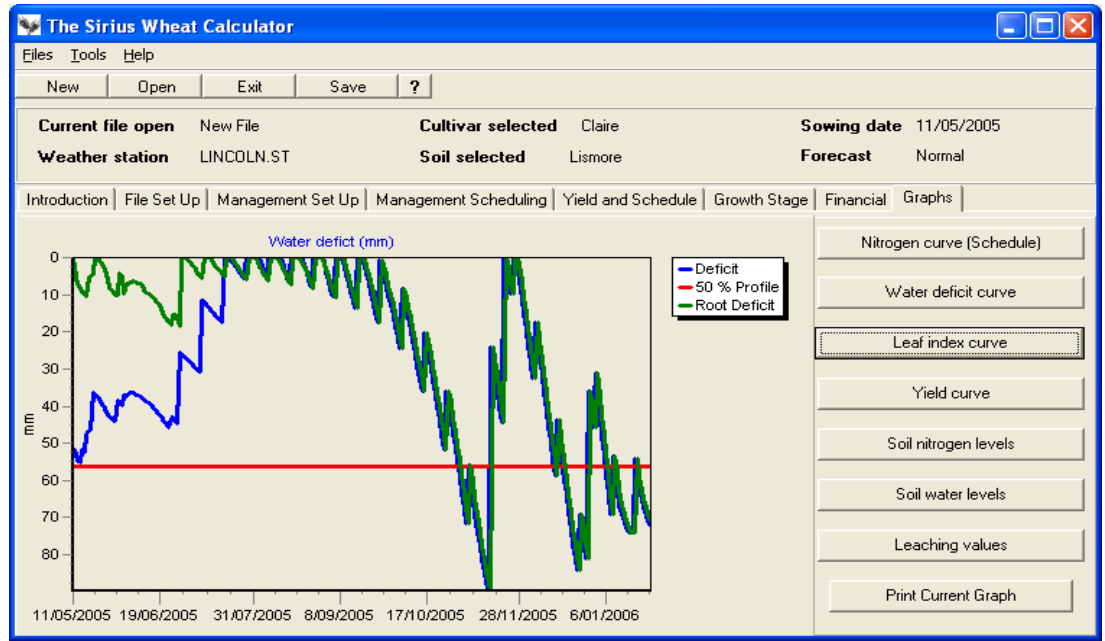

Figure 6: Output screen from the Sirius Wheat Calculator showing the development of predicted potential soil moisture deficits over the season. 


\section{Acknowledgements}

We acknowledge financial support from New Zealand Dairy Insight, New Zealand Foundation for Research, Science and Technology, and New Zealand Foundation for Arable Research.

\section{References}

[1] Ryan, A.P., The climate and weather of Canterbury. New Zealand Meteorological Service Miscellaneous Publication 115 (17), 66p, 1987.

[2] New Zealand Soil Bureau, General survey of the soils of the South Island. New Zealand. NZ Soil Bureau Bulletin 27, 404p, 1968.

[3] Doak, M., Parminter, I., Horgan, G., Monk, R. \& Elliot, G., The economic value of irrigation in New Zealand. MAF Technical Paper No: 04/01. Ministry of Agriculture and Forestry, Wellington, New Zealand. 62p, 2004.

[4] Miller, M.G. \& Veltman, A., Proposed Canterbury Natural Resources Plan for river and groundwater allocation policies and the implications for irrigation dependent farming in Canterbury. Proceedings of the New Zealand Grassland Association 66, pp. 11-23, 2004.

[5] Penman, H.L., Irrigation at Woburn VII. Report Rothamsted Experimental Station for 1970, Part 2, pp. 147-170, 1971.

[6] French, B.K. \& Legg, B.J., Rothamsted Irrigation. Journal of Agricultural Science 92, pp. 15-37, 1979.

[7] Martin, R.J., Jamieson, P.D., Wilson, D.R. \& Francis, G.S., The use of a rainshelter to determine yield responses of Russet Burbank potatoes to soil water deficit. Proceedings of the Agronomy Society of New Zealand 20, pp. 99-101, 1990.

[8] Ritchie, J.T., Model for predicting evaporation from a row crop during incomplete cover. Water Resources Research 8, pp. 1204-1213, 1972.

[9] Martin, R.J., Wilson, D.R., Jamieson, P.D., Stone, P.J., Reid, J.B. \& Gillespie, R.B., A simple versatile model of crop yield response to water deficit. Proceedings of the 4th International Crop Science Congress, Brisbane, Australia, 26 September - 1 October 2004. Online. Http://www.cropscience.org.au/icsc2004/poster/1/5/618_martinrj.htm.

[10] Martin, R.J. \& Jamieson, P.D., The effect of timing and intensity of drought on the growth and yield of field peas. New Zealand Journal of Crop and Horticultural Science 24, pp. 167-174, 1996.

[11] Jamieson, P.D., Martin, R.J. \& Francis, G.S., Drought influences on grain yield of barley, wheat and maize. New Zealand Journal of Crop and Horticultural Science 23, pp. 55-66, 1995.

[12] Martin, R.J., Jamieson, P.D., Gillespie, R.N. \& Maley, S., Effect of timing and intensity of drought on the yield of Oats (Avena sativa L.). Proceedings $10^{\text {th }}$ Australian Agronomy Conference, Hobart. 2001. Online. Http//www.regional.org.au/au/asa/2001/b/martin.htm. 
[13] Martin, R.J., Gillespie, R.N., Maley, S. \& Robson, M.B., Effect of timing and intensity of drought on the yield of white clover (Trifolium repens L.). Proceedings $11^{\text {th }}$ Australian Agronomy Society, Geelong. 2003. Online. Http//www.regional.org.au/au/asa/2003/c/14/martin.htm.

[14] Jamieson, P.D., Reid, J.B., Halse, S.J., Tregurtha, C.S. \& Martin, R.J., Nutrition and water effects on grain production in wheat - a combined model approach. Agronomy New Zealand 31, pp. 45-52, 2001.

[15] Armour, T, Jamieson, P.D. \& Zyskowski, R.F., Testing the Sirius Wheat Calculator. Agronomy New Zealand 32, pp. 1-6, 2002.

[16] Jamieson, P.D., Semenov, M.A., Brooking, I.R. \& Francis, G.S., Sirius: a mechanistic model of wheat response to environmental variation. European. Journal of Agronomy 8, pp. 161-179, 1998.

[17] Woodward, S.J.R., Barker, D.J., Zyskowski, R.F., A practical model for predicting soil water deficit in New Zealand pastures. New Zealand Journal of Agricultural Research 44, pp. 91-109, 2001.

[18] Moss, R.A., Fraser, T.J., Daly, M.J., Knight, T.L. \& Carson, D.G., The effect of pasture species on pasture and animal performances in irrigated systems. Proceedings of the New Zealand Grassland Association 62, pp. 59-66, 2000.

[19] Page Bloomer Associates, Irrigation evaluation code of practice 2006 Online. Http://www.pagebloomer.co.nz/irrigevalservices.html.

[20] McIndoe, I., Testing of irrigation best management guidelines 1998-1999. MAF Technical Paper No: 04/01 Ministry of Agriculture and Forestry, Wellington, New Zealand. 35p, 1999.

[21] Aqualink, Irrigation efficiency gaps - Review and Stock Take. Aqualink Report L05264/2, 2006. Online. Http://www.maf.govt.nz/sff/whatson/irrigation-efficiency-gaps.pdf. 